\title{
Systematic review of 2008-2012 literature and update of recommendations for the use of methotrexate in rheumatic diseases, with a focus on rheumatoid arthritis
}

\author{
M. Todoerti' , W. Maglione ${ }^{2}$, E. Bernero ${ }^{3}$, A. Bortoluzzi ${ }^{4}$, M. Colaci ${ }^{5}$, E. Galuppi ${ }^{4}$, \\ S. Paolino ${ }^{3}$, R. Talarico ${ }^{6}$, M. Cutolo ${ }^{3}$, C. Ferri ${ }^{5}$, F. Trotta ${ }^{4}$, S. Bombardieri', \\ C. Maurizio Montecucco ${ }^{1}$, L. Sinigaglia ${ }^{2}$ \\ ${ }^{1}$ Rheumatology, IRCCS S. Matteo, University of Pavia; ${ }^{2}$ Rheumatology, Istituto Ortopedico G. Pini, Milan; \\ ${ }^{3}$ Rheumatology, University of Genoa; ${ }^{4}$ Rheumatology, University of Ferrara; \\ ${ }^{5}$ Rheumatology, University of Modena and Reggio Emilia; ${ }^{6}$ Rheumatology, University of Pisa, Italy
}

\begin{abstract}
SUMMARY
The objective of this review is to update the recommendations of the 2010 Italian Consensus on the use of methotrexate (MTX) in rheumatoid arthritis (RA) and other rheumatic diseases. The literature published between 2008 and 2012 was systematically reviewed and updated recommendations on MTX use in rheumatic diseases, particularly RA, were formulated. These recommendations were approved by a panel of expert Italian Rheumatologists. A total of 10,238 references were identified, among which 70 studies were selected for critical evaluation. Sufficient evidence had accumulated to warrant changes to several of the recommendations in the new version. A new recommendation for patients with RA who are in MTX-induced clinical remission was also proposed and approved by the panel. Updated recommendations for the use of MTX in patients with RA or other rheumatologic disease are proposed.
\end{abstract}

Key words: Recommendations, Evidence-based medicine, Methotrexate, Rheumatoid arthritis, Rheumatic diseases.

Reumatismo, 2013; 65 (5): 207-218

\section{INTRODUCTION}

In n 2008, the international $3 E$ Initiative resulted in development of 10 evidencebased recommendations for the use of methotrexate (MTX) in rheumatic disorders based on analysis of scientific literature published before November 2007 and expert opinion. In 2009, national recommendations on the use of MTX in Rheumatology were formulated at an Italian Consensus Meeting. On this occasion, the 10 international recommendations along with five recommendations added by the Italian team, were discussed and reformulated, including an appraisal of the strength of the recommendation in the final version. The aim of the initiative was to standardize the Italian therapeutic approach to the use of MTX in rheumatoid arthritis (RA) and other rheumatic diseas- es to avoid heterogeneous conduct based on personal experience (1). The ICARUS Project was established with the aim of updating the previous recommendations, focusing on important aspects such as safety, starting dose, step-up strategy and route of administration.

\section{METHODS OF RESEARCH}

Under the guidance of a Scientific Committee comprised of six experts, eight bibliographic fellows specialized in Rheumatology systematically reviewed the scientific literature available regarding the 2010 Italian recommendations on the use of MTX in RA. In particular, previous recommendations were reassessed in light of studies on MTX published after November 2007 in order to address emerging clinical issues. $\overline{\text { Corresponding author: }}$ Michele Colaci U.O. Reumatologia Azienda Ospedaliero-Universitaria di Modena Policlinico di Modena

Via del Pozzo, 71 - 41100 Modena, Italy E-mail: michelecolaci@virgilio.it 
A total of 15 issues were identified and submitted to specific rephrasing and coding following the PICO method (Population, Intervention, Comparison, Outcome), in order to facilitate the literature review.

PubMed and Embase were consulted, selecting the literature related to the therapeutic use of MTX in rheumatic diseases (particularly RA) published between 2008 and September 2012.

The literature search was conducted according to Cochrane collaboration guidelines (2) and the results were critically analysed by the bibliographic fellows, following the principles of evidence-based medicine (3).

Each issue was analysed independently by two fellows, who produced preliminary observations and assigned a level of scientific evidence (4); finally, the updated issues were presented to the panel of experts in order to define topics for discussion.

Subsequently, a group of 36 Italian Rheumatologists attended a meeting structured in two specific sessions. In the first session, the participants were divided into coordinator-led subgroups in which the topics that emerged from the review were discussed, proposals were made, and preliminary recommendations were formu-

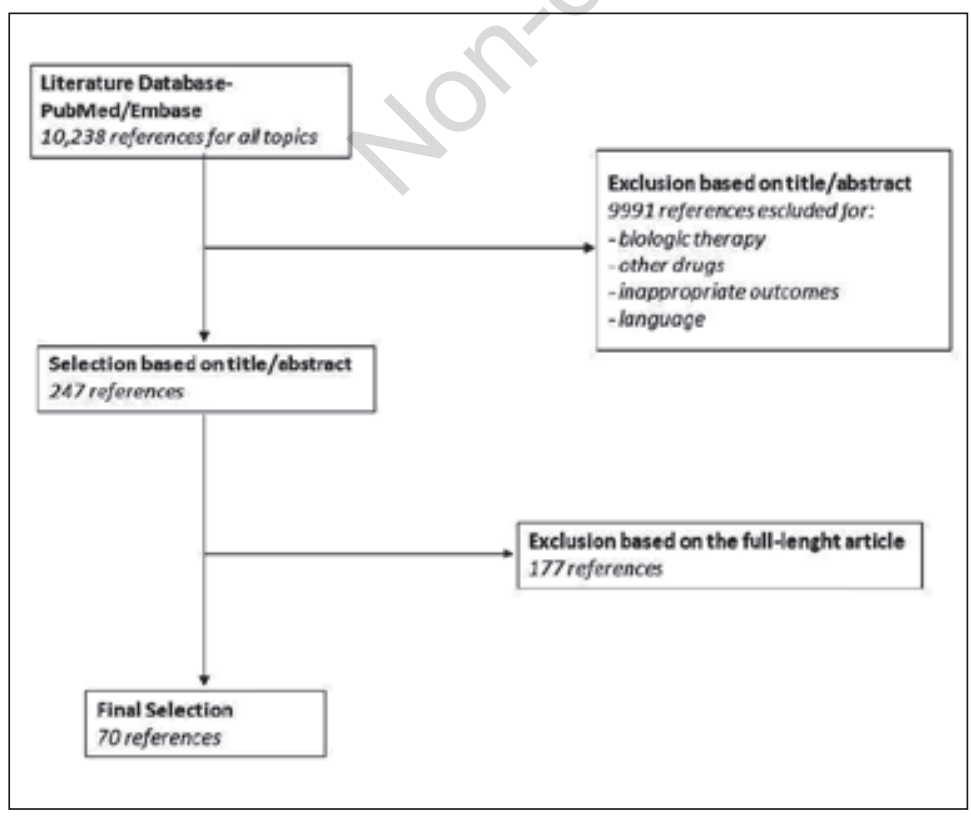

Figure 1 - Papers evaluated and reasons for exclusion. lated. In the second plenary session, the text of the preliminary recommendations was discussed and their acceptability determined by a Delphi-like procedure.

The text of the updated recommendations was thus finalized, adding the level of agreement that had emerged from the plenary vote.

\section{RESULTS}

Papers evaluated and reasons for exclusion are shown in Figure 1. Fifteen updated recommendations were released; to note that the original recommendation 7 (regarding MTX-naïve patients or MTX non-responder patients) was grouped with recommendations 11 and 12 , due to the presence of many overlapping elements.

Moreover, a new recommendation was introduced (recommendation 15) on the therapeutic approach for RA patients who have achieved clinical remission with MTX, alone or in combination with other agents (Table I).

Recommendation 1: work-up for methotrexate candidates

The work-up for RA patients who are MTX candidates should include the following tests: liver function tests; serum albumin; blood cell counts; serum creatinine; hepatitis $B$ and $C$ serology; chest $X$-ray. MTX treatment should not be introduced during pregnancy or in the presence of hepatic cirrhosis, severe renal function impairment; alcohol abuse; bone marrow depression; or active hepatitis $B$ or $C(4 ; C)$.

The prerequisite pregnancy test has been removed in the latest version, but the warning remains that this teratogenic drug must not be used when pregnancy is confirmed or suspected. Specific concomitant diseases and alcohol abuse remain contraindications to the administration of MTX (5-11). In particular, the literature supports the potential hepatotoxicity of MTX and its potential role in the reactivation of hepatitis $\mathrm{B}$, including acute fulminant hepatitis.

The recommendation was approved by $90.2 \%$ of participants. 
Table I - 2012 recommendations for the use of methotrexate in rheumatoid arthritis and in other rheumatic diseases.

\begin{tabular}{|c|c|}
\hline Recommendation (level of evidence; strength of the recommendation) & $\begin{array}{l}\text { Changes in } \\
\text { comparison with } \\
\text { the } 2010 \text { version }\end{array}$ \\
\hline $\begin{array}{l}\text { 1. The work-up for RA patients who are MTX candidates should include the following tests: liver } \\
\text { function tests; serum albumin; blood cell counts; serum creatinine; hepatitis B and C serology; } \\
\text { chest X-ray. MTX treatment should not be introduced during pregnancy or in the presence of } \\
\text { hepatic cirrhosis, severe renal function impairment; alcohol abuse; bone marrow depression; or } \\
\text { active hepatitis B or C (4; C). }\end{array}$ & Partially modified \\
\hline $\begin{array}{l}\text { 2. The therapeutic range of MTX is } 7.5-25 \mathrm{mg} / \text { week. The optimal initial strategy is a starting } \\
\text { dose of } 12.5-15 \mathrm{mg} / \text { week ( } 1 \mathrm{~b} \text {; B). In the absence of adverse events and/or subjective intoleran- } \\
\text { ce, in patients with early RA, close monitoring of therapeutic efficacy and therapeutic targets } \\
\text { with rapid up-titration ( } 5 \mathrm{mg} / \text { week a month) is more effective ( } 1 \mathrm{~b} \text {; B). As MTX-related toxicity is } \\
\text { dose-dependent, the maximum weekly dose of } 25 \mathrm{mg}(2 \mathrm{~b} \text {; B) should not be exceeded. It can } \\
\text { be given initially by oral or parenteral route. Oral bioavailability of the drug varies, in particular at } \\
\text { high doses ( } 3 \mathrm{~b} \text {; B). Parenteral MTX can increase efficacy with a similar safety profile ( } 1 \mathrm{~b} \text {; B). In } \\
\text { patients refractory to oral MTX, switching to parenteral administration may be a useful strategy } \\
\text { before introducing other therapies ( } 2 \mathrm{~b} \text {; B). }\end{array}$ & $\begin{array}{l}\text { Extensively } \\
\text { modified }\end{array}$ \\
\hline $\begin{array}{l}\text { 3. Weekly supplementation with folic acid ( } 5-10 \mathrm{mg} / \text { week) should be administered to reduce } \\
\text { the risk of adverse events/intolerance (1a; A). In most cases, it should be taken } 24 \text { hours after } \\
\text { MTX. To date there is sufficient evidence that folic acid supplements do not nullify the clinical } \\
\text { efficacy of MTX (1a; A). }\end{array}$ & Partially modified \\
\hline $\begin{array}{l}\text { 4. Transaminases (AST, ALT) are the most useful laboratory parameters for monitoring liver to- } \\
\text { xicity due to MTX. CBC and renal function tests should also be performed in patients receiving } \\
\text { MTX. These tests should be performed every } 2 \text { weeks for the first month, then every } 4-12 \text { weeks } \\
\text { to check for hepatic, haematological or renal toxicity }(1 ; A) \text {. Neither chest X-rays nor respiratory } \\
\text { function tests allow prediction of the risk of MTX pneumonia }(4 ; C) \text {. }\end{array}$ & Unchanged \\
\hline $\begin{array}{l}\text { 5. When liver enzymes increase ( } \geq 2 x \text { normal upper limit), the dosage of MTX must be reduced or } \\
\text { administration discontinued temporarily. Persistently high values indicate that treatment should } \\
\text { be discontinued. A liver biopsy is indicated when liver enzyme values are persistently high de- } \\
\text { spite treatment discontinuation and when other risk factors for liver disease are present ( } 2 \mathrm{~b} ; \mathrm{C}) \text {. }\end{array}$ & Unchanged \\
\hline $\begin{array}{l}\text { 6. According to its safety profile, MTX may be used for long-term therapy. Discontinuation rates } \\
\text { due to toxicity are similar to those in patients treated with hydroxychloroquine or leflunomide, } \\
\text { and lower than those in patients receiving gold salts or sulfasalazine (3b; B). The most frequent } \\
\text { side effects during treatment with MTX are gastrointestinal disturbances, with constant inciden- } \\
\text { ce over time, and hypertransaminasemia, especially during the first } 5 \text { years. The discontinuation } \\
\text { rate due to hepatotoxicity is about } 5 \% \text {. Alcohol consumption should be avoided, because it } \\
\text { appears to be an adjunctive risk factor for the development of hepatic fibrosis. MTX is not a } \\
\text { significant risk factor for the development of infections, including severe infections. In patients } \\
\text { with RA, MTX, and DMARDs in general, are associated with a greater incidence of tuberculosis } \\
\text { reactivation (3b; B). MTX does not appear to be a risk factor for the development of neoplasms } \\
\text { (3b; B). MTX can prolong the survival of RA patients by reducing cardiovascular mortality (2a; A). }\end{array}$ & Partially modified \\
\hline $\begin{array}{l}\text { 7. The administration of MTX (at } \leq 10 \mathrm{mg} / \text { week) can be continued in RA patients who undergo } \\
\text { orthopaedic surgery as MTX does not affect the incidence of perioperative surgical complica- } \\
\text { tions whereas treatment discontinuation may increase the incidence of disease reactivation. } \\
\text { MTX dosage reduction or treatment discontinuation may be considered for doses } \geq 10 \mathrm{mg} \text { per } \\
\text { week in patients undergoing major surgery }(1 \mathrm{~b} \text {; B). }\end{array}$ & Unchanged \\
\hline $\begin{array}{l}\text { 8. MTX must be discontinued at least } 3 \text { months before conception (both in men and in women), } \\
\text { it must be strictly forbidden during pregnancy and avoided during breastfeeding }(4 ; C) \text {. }\end{array}$ & Unchanged \\
\hline $\begin{array}{l}\text { 9. MTX must be considered the DMARD of first choice in RA patients both alone and in combi- } \\
\text { nation (with low dosage glucocorticoid and/or other DMARDs) (2b; B). }\end{array}$ & Partially modified \\
\hline $\begin{array}{l}\text { 10. In patients that are non-responders to MTX at the maximum tolerated dosage, combina- } \\
\text { tion therapy can be started with DMARD or a biological agent ( } 1 \mathrm{~b} ; \mathrm{B}) \text {. Currently, addition of a } \\
\text { biological agent should be preferred in patients with poor prognostic factors or documented } \\
\text { radiological progression ( } 1 \mathrm{~b} ; \mathrm{B}) \text {. }\end{array}$ & Partially modified \\
\hline $\begin{array}{l}\text { 11. Administration of MTX must be temporarily discontinued in patients who develop severe } \\
\text { infections (any infection requiring hospitalization and/or intravenous antibiotics/antifungals and/ } \\
\text { or presenting with sepsis or is life-threatening, according to the } \mathrm{NIH})(5 ; \mathrm{D}) \text {. }\end{array}$ & Unchanged \\
\hline
\end{tabular}




\begin{tabular}{|l|l|}
\hline Recommendation (level of evidence; strength of the recommendation) & $\begin{array}{l}\text { Changes in } \\
\text { comparison with } \\
\text { the 2010 version }\end{array}$ \\
\hline 12. Administration of MTX must be discontinued temporarily in patients who develop neutro- \\
penia (neutrophil count $<1000$ ). MTX can be reintroduced with caution in patients who have not \\
developed other adverse reactions in association with neutropenia (e.g., infections) and where \\
neutropenia has resolved spontaneously, after having considered the concomitant association \\
with other risk factors for haematological toxicity (5; D).
\end{tabular}

MTX, methotrexate; RA, rheumatoid arthritis; DMARD, disease-modifying antirheumatic drug; GCA, giant cell arteritis; PMR, rheumatic polymyalgia; SLE, systemic lupus erythematosus; AAV, ANCA-associated vasculitis; PsA, peripheral psoriatic arthritis.

\section{Recommendation 2: methotrexate thera- peutic strategy}

The therapeutic range of MTX is 7.5-25 $\mathrm{mg} /$ week. The optimal initial strategy is a starting dose of 12.5-15 mg/week (1b). In the absence of adverse events and/or subjective intolerance, in patients with early RA, close monitoring of therapeutic efficacy and therapeutic targets with rapid up-titration (5 $\mathrm{mg} /$ week a month) is more effective (1b). As MTX-related toxicity is dose-dependent, the maximum weekly dose of $25 \mathrm{mg}(2 \mathrm{~b})$ should not be exceeded. It can be given initially by oral or parenteral route. Oral bioavailability of the drug varies, in particular at high doses (3b). Parenteral MTX can increase efficacy with a similar safety profile (1b). In patients refractory to oral MTX, switching to parenteral administration may be a useful strategy before introducing other therapies (2b).

The text has been extensively modified in the latest version, focusing on the best therapeutic strategy: the optimal starting and step-up doses of MTX have been specified, indicating the best timing and methods, and considering the safety profile. In addition, it has been established that parenteral MTX is more effective than oral MTX, both in MTX naïve patients and in those refractory to administration per os (12-16), whereas the safety of the two formulations is similar.

The recommendation was approved by $97.3 \%$ of participants.

\section{Recommendation 3: folate supplementa- tion}

Weekly supplementation with folic acid (5$10 \mathrm{mg} /$ week) should be administered to reduce the risk of adverse events/intolerance (1a). In most cases, it should be taken 24 hours after MTX. To date there is sufficient evidence that folic acid supplements do not nullify the clinical efficacy of MTX (1a).

The need for both low and high dose folic acid supplementation (less than or more than $5 \mathrm{mg}$ /week) was confirmed, to reduce MTX-related adverse events, such as hepa- 
totoxicity, and gastrointestinal and mucocutaneous intolerance. However, there is no conclusive evidence supporting the protection afforded by folic acid against bone marrow toxicity, either due to the low incidence of these haematological adverse events reported with the use of MTX, or to the inaccurate definition of this adverse effect in some studies. In addition, according to available data, folic acid supplementation does not appear to interfere with the therapeutic efficacy of MTX $(17,18)$. On the other hand, to date, there is no evidence that folinic acid, either at low or high dosage (less than/more than $5 \mathrm{mg} /$ week), offers additional benefit compared to folic acid for reducing/preventing MTX-related adverse events/intolerance. Furthermore, some evidence suggests that it may interfere with the efficacy of MTX (increasing the number of tender joints). Moreover, higher costs would not justify folic acid replacement (18).

The recommendation was approved by $89.5 \%$ of participants.

\section{Recommendation 4: monitoring for liver toxicity}

Transaminases (AST, ALT) are the most useful laboratory parameters for monitoring liver toxicity due to MTX. Blood cells count and renal function tests should also be performed in patients receiving MTX. These tests should be performed every 2 weeks for the first month, then every 4-12 weeks to check for hepatic, haematological or renal toxicity $(1 ; A)$. Neither chest X-rays nor respiratory function tests allow prediction of the risk of MTX pneumonia (4; C).

This recommendation is unchanged in the new version, as no new significant evidence was found in the literature. Recent studies confirm previous findings $(19,20)$. The recommendation was approved by $90.2 \%$ of participants.

Recommendation 5: actions in the event of increased liver enzymes

When liver enzymes increase ( $\geq 2 x$ normal upper limit), the dosage of MTX must be reduced or administration discontinued temporarily. Persistently high values indicate that treatment should be discontinued. A liver biopsy is indicated when liver enzyme values are persistently high despite treatment discontinuation and when other risk factors for liver disease are present $(2 b ; C)$. Nothing emerged from the literature review that warranted substantial changes to the 2010 recommendation. There were no new randomized controlled trials (RCTs) comparing possible strategies for dealing with elevated liver enzyme levels during MTX treatment. The importance of reducing the dose, or temporary discontinuing therapy was confirmed (21, 22-25).

The recommendation was approved by $89.2 \%$ of participants.

\section{Recommendation 6: long-term use of methotrexate}

According to its safety profile, MTX may be usedfor long-term therapy. Discontinuation rates due to toxicity are similar to those in patients treated with hydroxychloroquine or leflunomide, and lower than those in patients receiving gold salts or sulfasalazine (3b). The most frequent side effects during treatment with MTX are gastrointestinal disturbances, with constant incidence over time, and hypertransaminasemia, especially during the first 5 years. The discontinuation rate due to hepatotoxicity is about $5 \%$. Alcohol consumption should be avoided, because it appears to be an adjunctive risk factor for the development of hepatic fibrosis. MTX is not a significant risk factor for the development of infections, including severe infections. In patients with RA, MTX, and DMARDs in general, are associated with a greater incidence of tuberculosis reactivation ( $3 b$ ). MTX does not appear to be a risk factor for the development of neoplasms (3b). MTX can prolong the survival of $R A$ patients by reducing cardiovascular mortality (2a).

In view of the safety profile of the drug, the 2010 recommendation that MTX is appropriate for long-term use has been unequivocally confirmed. In addition, leflunomide has been added to the list of other diseasemodifying antirheumatic drugs (DMARDs) that have been compared with MTX; its discontinuation rate due to adverse events 
is comparable with that of $\operatorname{MTX}(26,27)$. Concerning the risk of infections during MTX treatment, there is no specific risk for the development of a number of types of infections (including herpes zoster infections and post-operative infections); however, as with other DMARDs, there was an increased incidence of tuberculosis $(28,29)$. The absence of an increased risk of neoplasms was confirmed. Finally, the drug provides a potential protective effect against cardiovascular mortality in patients with RA treated with MTX who have concomitant heart disease (30-33).

The recommendation was approved by $90.2 \%$ of participants.

Recommendation 7: treatment with methotrexate in the event of orthopaedic surgery

The administration of MTX (at $\leq 10 \mathrm{mg}$ ) week) can be continued in RA patients who undergo orthopaedic surgery as MTX does not affect the incidence of perioperative surgical complications, whereas treatment discontinuation may increase the incidence of disease reactivation. MTX dosage reduction or treatment discontinuation may be considered for doses $>10 \mathrm{mg}$ per week in patients undergoing major surgery $(1 b ; B)$. This recommendation, corresponding to number 8 in the 2010 version, remains unchanged in the present version, as no new evidence was found in the literature. The most recent publications have confirmed the result of previous studies. However, their findings are confined to low dose oral MTX given to patients undergoing orthopaedic surgery (34). There is no data on the use of higher doses, administered by parenteral route and to patients undergoing non-orthopaedic surgery. Thus, treatment decisions in individual cases must be made by the clinician (and surgeon) based on the patient's condition and comorbidities, in particular on the global surgical and infection risk profile, the type of intervention proposed and on current therapy (whether combined with corticosteroids and/or other DMARDs).

The recommendation was approved by $85.4 \%$ of participants.
Recommendation 8: treatment with methotrexate and conception

MTX must be discontinued at least 3 months before conception (both in men and in women), it must be strictly forbidden during pregnancy and avoided during breastfeeding $(4 ; C)$.

This recommendation, corresponding to number 9 in the 2010 version, has not been changed in the new version due to the lack of new evidence in the literature. The most recent publications have confirmed what had been reported previously (35-37).

The recommendation was approved by $76.5 \%$ of participants.

Recommendation 9: methotrexate as the first choice in rheumatoid arthritis patients

MTX must be considered the DMARD of first choice in RA patients both alone and in combination (with low dosage glucocorticoid and/or other DMARDs) (2b).

The evidence currently available, obtained from one meta-analysis and one doubleblind controlled RCT conducted on a cohort of patients with early RA, shows that, in the context of an MTX-based therapeutic strategy (titrating MTX to the maximum tolerated dose and in any case to not more than $25 \mathrm{mg} /$ week until remission is achieved), the addition of a low-dose steroid improves outcomes, in terms of reduced radiographic progression and/or lower disease activity and less disability (38-42).

The recommendation was approved by $94.4 \%$ of participants.

Recommendation 10: combined therapy in methotrexate non-responder patients In patients that are non-responders to MTX at the maximum tolerated dosage, combination therapy can be started with DMARD or a biological agent (1b). Currently, addition of a biological agent should be preferred in patients with poor prognostic factors or documented radiological progression (1b). This recommendation has been amended in comparison with recommendation number 12 in the 2010 version. A Cochrane review revealed that, considering the risk/benefit ratio, there is no statistically significant 
advantage to combining MTX with other DMARDs compared to MTX alone when treating MTX naïve or MTX non-responder patients (43). The only combination with a better risk/benefit profile than MTX alone was MTX + Hydroxychloroquine + Sulfasalazine (44). Two recent studies have compared the efficacy and safety of this triple combination therapy to that of anti-TNF, revealing that the addition of a biological drug (not only anti-TNF) improves both clinical and radiological outcomes (45-48).

The recommendation was approved by $76.5 \%$ of participants.

Recommendation 11: discontinuation of methotrexate in the event of severe infections

Administration of MTX must be temporarily discontinued in patients who develop severe infections (any infection requiring hospitalization and/or intravenous antibiotics/antifungals and/or presenting with sepsis or is life threatening, according to the NIH) $(5 ; D)$.

This recommendation has not been modified in comparison with number 13 in the 2010 version, because no new data emerged from the literature. Considering the immunosuppressive properties of MTX, the recommendation to suspend administration of the drug temporarily was considered appropriate (49).

The recommendation was approved by $94.7 \%$ of participants.

Recommendation 12: discontinuation of methotrexate in the event of neutropenia Administration of MTX must be discontinued temporarily in patients who develop neutropenia (neutrophil count <1000). MTX can be reintroduced with caution in patients who have not developed other adverse reactions in association with neutropenia (e.g., infections) and where neutropenia has resolved spontaneously, after having considered the concomitant association with other risk factors for haematological toxicity $(5 ; D)$.

No evidence has emerged to justify updating this recommendation. In some obser- vational studies, predictors of the onset of haematological toxicity were: renal failure, hypoalbuminemia, low blood levels of folic acid, absence of folic supplementation, old age, concomitant infection and pharmacological polytherapy. Therefore, when these risk factors are present, the clinician should be alert for signs of potential myelotoxicity. However, it was pointed out that haematological toxicity of MTX is rare and may appear both early (idiosyncratic reaction) and late (time- and dose-dependent) (50). The recommendation was approved by $97.1 \%$ of participants.

Recommendation 13: interventions in the event of nodulosis

MTX can be administered to patients with pre-existing rheumatoid nodules. The dosage of MTX should be reduced or administration should be discontinued in patients who develop accelerated nodulosis during treatment $(5 ; D)$.

This recommendation has not been changed in comparison with number 15 in the 2010 version, due to the lack of new evidence. Worthy of note is that the 2010 Italian Consensus indicated that accelerated nodulosis should be addressed to the individual patient considering balance between residual disease activity and beneficial response to MTX therapy versus the possibility and the magnitude of side effects related to the drug (1).

The recommendation was approved by $97.1 \%$ of participants.

Recommendation 14: methotrexate in non-rheumatoid arthritis diseases

MTX can be used:

- as a glucocorticoid-sparing drug in the long-term treatment of patients with giant cell arteritis (GCA) (1a), recent-onset rheumatic polymyalgia (PMR) $(1 b)$, mildto-moderate SLE with mainly skin and joint involvement $(1 b)$;

- to induce clinical remission in patients with recent-onset ANCA-associated vasculitis $(A A V)$ with early systemic involvement (1b). It can also replace Azathioprine for the maintenance of CTX-induced clinical remission $(1 b)$; 
- in peripheral psoriatic arthritis (PsA), effective mainly on the cutaneous involvement, but also efficacious on the joint component $(1 b ; B)$.

A few data also supports the possible use of MTX as an agent that can improve cutaneous involvement in recent-onset and widespread systemic sclerosis without significant organ involvement (1b).

No evidence was found that warranted an update of the recommendation (51-54), in particular regarding the use of MTX in patients with recent-onset PMR and GCA (average disease duration $<6$ months) and with systemic lupus erythematosus (SLE). The current version, however, has extended the use of MTX to other non-RA diseases for which sufficiently valid supporting scientific evidence (RCT) exists, including ANCA-associated vasculitis (AAV), in particular granulomatosis with polyangiitis (Wegener's) and micropolyangiitis (51, 55), psoriatic arthritis (PsA) (56-61) and systemic sclerosis (SSc) without significant organ involvement, especially without renal or pulmonary involvement (62).

The recommendation was approved by $91.2 \%$ of participants.

Recommendation 15: possible discontinuation of treatment with methotrexate due to achievement of clinical remission

Therapeutic approach to $R A$ patients who have achieved clinical remission with MTX alone or in combination with other agents. In RA patients treated early (within 1 year of symptoms onset) who achieve and maintain clinical remission for $\geq 12$ months, independently of the "tight control" therapeutic strategy and the DMARD discontinuation methods adopted, treatment (including MTX) can be discontinued in the attempt to achieve a "drug free remission", which is feasible in 17-29\% of patients.

In this recommendation, which was introduced de novo in comparison with the original recommendations, attention has been focused for the first time on the therapeutic strategy to use for patients with RA who achieve MTX-induced clinical remission. In addition to the scarcity of studies on this subject, comparisons were hindered by the heterogeneous nature of the studies in terms of target populations, the definition and criteria identifying clinical remission and the therapeutic strategies adopted. Nevertheless, the analysis of the literature revealed that clinical remission is obtained more frequently in patients treated initially with combined therapy (with biological agents or DMARDs) or tightly controlled intensive therapy in comparison with those who receive standard treatment, i.e., DMARD alone or non-intensive conventional management. It should be pointed out that discontinuing DMARDs, in the attempt to achieve drug-free remission, can be safely implemented only in a small percentage of patients (63-69). There is no evidence supporting any one DMARD discontinuation method over another; the drug-free remission rate is $12 \%$ after five years of follow-up (70).

The recommendation was approved by $85.7 \%$ of participants.

\section{DISCUSSION}

This update of the 2010 Italian recommendations on the use of MTX in rheumatic diseases, is the result of a detailed review of the literature published between 2008 and 2012 on the treatment of patients with RA or non-RA rheumatologic diseases with MTX. The recommendations are based on a high level of evidence, showing the robustness of the qualitative and quantitative supporting data used, which was generally obtained from important studies (meta-analyses and RCTs). As in 2010, the complexity of the topic MTX in rheumatology is reflected in the variety of the issues investigated, with addition of the new topic on the therapeutic approach to patients with RA in remission. The literature analysis revealed that clinical research is focused on determining the best therapeutic strategy, the safety profile and the potential efficacy of combination therapies. Thus, it may be assumed that early and intensive treatment could be more effective in order to preserve joint function and quality of life.

As in the recommendations formulated by 
the American College of Rheumatology (71), the present recommendations have been drawn up considering the typical patient and are therefore fully applicable to clinical practice only after the clinician evaluates the individual risk/benefit ratio and adapts the treatment proposed for each patient.

In summary, this update offers indications for good clinical practice, in order to support the Rheumatologist in addressing a number of common clinical issues, in light of evidence-based medicine.

Obviously, the publication of new scientific findings, as well as the emergence of new significant clinical issues, will determine the need for further modifications and updates of these recommendations.

\section{ACKNOWLEDGEMENTS}

The Authors acknowledge all the participants in the ICARUS project: Luisa Arcarese, Chiara Arcuri, Gianfilippo Bagnato, Mario Bentivegna, Gerolamo Bianchi, Patrizia Bigo, Massimo Bracci, Renzo Caradonna, Michele Covelli, Giovanni D'Avola, Tito D'Errico, Renato De Stefano, Maria Chiara Ditto, Fortunato Ferracane, Matteo Filippini, Pierluigi Frugiuele, Pietro Garau, Daniela Grembiale, Maria Domenica Guarino, Serena Guiducci, Giovanni Italiano, Ciro Lauriti, Claudia Lomater, Elide Lupi, Helal Mahamid, Marco Massarotti, Saverio Naty, Alfonso Oriente, Roberta Pellegrini, Pierpaolo Sainaghi, Piercarlo Sarzi Puttini, Magda Scarpellini, Crescenzio Scioscia, Monica Spataro, Chiara Tani, Simona Truglia.

\section{REFERENCES}

1. De Leonardis F, Alivernini S, Bonacci E, Buono AM, Bombardieri S, Ferraccioli GF, et al. Italian consensus on the recommendations about the use of methotrexate for the treatment of rheumatic diseases with a focus on rheumatoid arthritis: results from the " $3 \mathrm{E}$ initiative". Reumatismo. 2010; 62: 34-45.

2. van Tulder M, Furlan A, Bombardier C, Bouter L; Editorial Board of the Cochrane Collaboration Back Review Group. Updated me- thod guidelines for systematic reviews in the cochrane collaboration back review group. Spine (Phila Pa 1976). 2003; 28: 1290-9.

3. Sackett DL, Richardson WS, Rosemberg WM, Haynes RB. Evidence-based medicine: how to practice and teach EBM. London: Churchill Livingstone, 1997.

4. Oxford Centre for Evidence Based medicine. Levels of evidence (March 2009). Available from: http://www.cebm.net/index.aspx? $\mathrm{o}=1025 /$ Accessed: November 2012.

5. Arena U, Stasi C, Mannoni A, Benucci M, Maddali-Bongi S, Cammelli D, et al. Liver stiffness correlates with methotrexate cumulative dose in patients with rheumatoid arthritis. Dig Liver Dis. 2012; 44: 149-53.

6. Martínez Lopez JA, Loza E, Carmona L. Systematic review on the safety of methotrexate in rheumatoid arthritis regarding the reproductive system (fertility, pregnancy, and breastfeeding). Clin Exp Rheumatol. 2009; 27: 678-84.

7. Oshima Y, Tsukamoto H, Tojo A. Association of hepatitis B with antirheumatic drugs: a case-control study. Mod Rheumatol. 2013; 23 : 694-704.

8. Watanabe K, Takase K, Ohno S, Ideguchi H, Nozaki A, Ishigatsubo Y. Reactivation of hepatitis B virus in a hepatitis B surface antigennegative patient with rheumatoid arthritis treated with methotrexate. Mod Rheumatol. 2012; 22: 470-3.

9. Cobeta García JC, Medrano M. Reactivation of hepatitis B in a patient with spondyloarthritis after the suspension of methotrexate and efficacy of treatment with antivirals in association to adalimumab. Reumatol Clin. 2011; 7: 200-2.

10. Cabrera Villalba SR, Victoria Hernández Miguel M, Sanmartí Sala R. How does one manage patients with rheumatoid arthritis and positive serology to hepatitis $\mathrm{B}$, hepatitis $\mathrm{C}$, human immunodeficiency virus? Reumatol Clin. 2011; 7: 203-7.

11. Al-Hasani H, Roussou E. Methotrexate for rheumatoid arthritis patients who are on hemodialysis. Rheumatol Int. 2011; 31: 1545-7.

12. Visser K, van der Hejde D. Optimal dosage and route of administration of methotrexate in rheumatoid arthritis: a systematic review of the literature. Ann Rheum Dis. 2009; 68: 1094-9.

13. Bakker MF, Jacobs JW, Welsing PM, van der Werf JH, Linn-Rasker SP, van der Veen MJ, et al. Are switches from oral to subcutaneous methotrexate or addition of ciclosporin to methotrexate useful steps in a tight control treatment strategy for rheumatoid arthritis? A post hoc analysis of the CAMERA study. Ann Rheum Dis. 2010; 69: 1849-52. 
14. Braun J, Kästner P, Flaxenberg P, Währisch J, Hanke P, Demary W, et al. Comparison of the clinical efficacy and safety of subcutaneous versus oral administration of methotrexate in patients with active rheumatoid arthritis: results of a six-month, multicenter, randomized, double-blind, controlled, phase IV trial. Arthritis Rheum. 2008; 58: 73-81.

15. Vermeer M, Kuper HH, Hoekstra M, Haagsma CJ, Posthumus MD, Brus HL, et al. Implementation of a treat-to-target strategy in very early rheumatoid arthritis: results of the Dutch Rheumatoid Arthritis Monitoring remission induction cohort study. Arthritis Rheum. 2011; 63: 2865-72.

16. Mainman H, McClaren E, Heycock C, Saravanan V, Hamilton J, Kelly C. When should we use parenteral methotrexate? Clin Rheumatol. 2010; 29: 1093-8.

17. Prey S, Paul C. Effect of folic or folinic acid supplementation on methotrexate-associated safety and efficacy in inflammatory disease: a systematic review. Br J Dermatol. 2009; 160: 622-8.

18. Ortiz Z, Shea B, Suarez Almazor M, Moher D, Wells G, Tugwell P. Folic acid and folinic acid for reducing side effects in patients receiving methotrexate for rheumatoid arthritis. Cochrane Database Syst Rev. 2000; (2): CD000951.

19. Gilani ST, Khan DA, Khan FA, Ahmed M. Adverse effects of low dose methotrexate in rheumatoid arthritis patients. J Coll Physicians Surg Pak. 2012; 22: 101-4.

20. Bourrè-Tessier J, Haroui B. Methotrexate drug interactions in the treatment of rheumatoid arthritis: a systematic review. J Rheumatol. 2010; 37: 1416-21.

21. Verstappen SM, Bakker MF, Heurkens AH, van der Veen MJ, Kruize AA, Geurts MA, et al. Adverse events and factors associated with toxicity in patients with early rheumatoid arthritis treated with methotrexate tight control therapy: the CAMERA study. Ann Rheum Dis. 2010; 69: 1044-8.

22. Visser K, van der Heijde DM. Risk and management of liver toxicity during methotrexate treatment in rheumatoid and psoriatic arthritis: a systematic review of the literature. Clin Exp Rheumatol. 2009; 27: 1017-25.

23. Salliot C, van der Heijde D. Long-term safety of methotrexate monotherapy in patients with rheumatoid arthritis: a systematic literature research. Ann Rheum Dis. 2009; 68: 1100-4.

24. Khan N, Abbas AM, Whang N, Balart LA, Bazzano LA, Kelly TN. Incidence of liver toxicity in inflammatory bowel disease patients treated with methotrexate: a meta-analysis of clinical trials. Inflamm Bowel Dis. 2012; 18 : 359-67.
25. Curtis JR, Beukelman T, Onofrei A, Cassell S, Greenberg JD, Kavanaugh A, et al. Elevated liver enzyme tests among patients with rheumatoid arthritis or psoriatic arthritis treated with methotrexate and/or leflunomide. Ann Rheum Dis. 2010; 69: 43-7.

26. Ishaq M, Muhammad JS, Hameed K, Mirza AI. Leflunomide or methotrexate? Comparison of clinical efficacy and safety in low socio-economic rheumatoid arthritis patients. Mod Rheumatol. 2011; 21: 375-80.

27. Jaimes-Hernández J, Meléndez-Mercado CI, Mendoza-Fuentes A, Aranda-Pereira P, Castañeda-Hernández G. Efficacy of leflunomide $100 \mathrm{mg}$ weekly compared to low dose methotrexate in patients with active rheumatoid arthritis. Double blind, randomized clinical trial. Reumatol Clin. 2012; 8: 243-9.

28. Brassard P, Lowe AM, Bernatsky S, Kezouh A, Suissa S. Rheumatoid arthritis, its treatments and the risk of tuberculosis in Quebec, Canada. Arthritis Rheum. 2009; 61: 300-4.

29. Zhang N, Wilkinson S, Riaz M, Östör AJ, Nisar MK. Does methotrexate increase the risk of varicella or herpes zoster infection in patients with rheumatoid arthritis? A systematic literature review. Clin Exp Rheumatol. 2012; 30: 962-71.

30. Westlake SL, Colebatch AN, Baird J, Kiely P, Quinn M, Choy E, et al. The effect of methotrexate on cardiovascular disease in patients with rheumatoid arthritis: a systematic literature review. Rheumatology (Oxford). 2010; 49: 295-307.

31. Micha R, Imamura F, Wyler von Ballmoos M, Solomon DH, Hernán MA, et al. Systematic review and meta-analysis of methotrexate use and risk of cardiovascular disease. Am J Cardiol. 2011; 108: 1362-70.

32. Bozaite-Gluosniene R, Tang X, Kirchner HL, Antohe JL, Morris SJ, Wasko MC, et al. Reduced cardiovascular risk with use of Methotrexate and tumornecrosis factor-alpha inhibitors in patients with Rheumatoid Arthritis. 75th Annual Meeting of American College of Rheumatology 2011. Abstract 719.

33. Marks JL, Edwards CJ. Protective effect of methotrexate in patients with rheumatoid arthritis and cardiovascular comorbidity. Ther Adv Muscoloskelet Dis. 2012; 4: 149-57.

34. Sreekumar R, Gray J, Kay P, Grennan DM. Methotrexate and post operative complications in patients with rheumatoid arthritis undergoing elective orthopaedic surgery--a ten year follow-up. Acta Orthop Belg. 2011; 77: 823-6.

35. Viktil KK, Engeland A, Furu K. Outcomes after anti-rheumatic drug use before and during pregnancy: a cohort study among 150,000 pre- 
gnant women and expectant fathers. Scand J Rheumatol. 2012; 41: 196-201.

36. Makol A, Wright K, Amin S. Rheumatoid arthritis and pregnancy: safety considerations in pharmacological management. Drugs. 2011; 71: 1973-87.

37. Østensen M, Förger F. Management of RA medications in pregnant patients. Nat Rev Rheumatol. 2009; 5: 382-90.

38. Gaujoux-Viala C, Smolen JS, Landewé R, Dougados M, Kvien TK, Mola EM, et al. Current evidence for the management of rheumatoid arthritis with synthetic disease-modifying antirheumatic drugs: a systematic literature review informing the EULAR recommendations for the management of rheumatoid arthritis. Ann Rheum Dis. 2010; 69: 1004-9.

39. Bakker MF, Jacobs JW, Welsing PM, Verstappen SM, Tekstra J, Ton E, et al. Low-dose prednisone inclusion in a methotrexate-based, tight control strategy for early rheumatoid arthritis: a randomized trial. Ann Intern Med. 2012; 156: 329-39.

40. Graudal N, Jürgens G. Similar effects of disease-modifying antirheumatic drugs, glucocorticoids, and biologic agents on radiographic progression in rheumatoid arthritis: metaanalysis of 70 randomized placebo-controlled or drug-controlled studies, including $112 \mathrm{com}$ parisons. Arthritis Rheum. 2010; 62: 2852-63.

41. Montecucco C, Todoerti M, Sakellariou G, Scirè CA, Caporali R. Low-dose oral prednisone improves clinical and ultrasonographic remission rates in early rheumatoid arthritis: results of a 12-month open-label randomised study. Arthritis Res Ther. 2012; 14: R112.

42. Todoerti M, Scirè CA, Boffini N, Bugatti S, Montecucco C, Caporali R. Early disease control by low-dose prednisone comedication may affect the quality of remission in patients with early rheumatoid arthritis. Ann N Y Acad Sci. 2010; 1193: 139-45.

43. Katchamart W, Trudeau J, Phumethum V, Bombardier C. Methotrexate monotherapy versus methotrexate combination therapy with non-biologic disease modifying anti-rheumatic drugs for rheumatoid arthritis. Cochrane Database Syst Rev. 2010; (4): CD008495.

44. van Vollenhoven RF, Ernestam S, Geborek P, Petersson IF, Cöster L, Waltbrand E, et al. Addition of infliximab compared with addition of sulfasalazine and hydroxychloroquine to methotrexate in patients with early rheumatoid arthritis (Swefot trial): 1-year results of a randomised trial. Lancet. 2009; 374: 459-66.

45. van Vollenhoven RF, Geborek P, Forslind K, Albertsson K, Ernestam S, Petersson IF, et al. Conventional combination treatment versus biological treatment in methotrexate-refracto- ry early rheumatoid arthritis: 2 year follow-up of the randomised, non-blinded, parallel-group Swefot trial. Lancet. 2012; 379: 1712-20.

46. Emery P, Deodhar A, Rigby WF, Isaacs JD, Combe B, Racewicz AJ, et al. Efficacy and safety of different doses and retreatment of rituximab: a randomised, placebo-controlled trial in patients who are biological naïve with active rheumatoid arthritis and an inadequate response to methotrexate (Study Evaluating Rituximab's Efficacy in MTX iNadequate rEsponders (SERENE)). Ann Rheum Dis. 2010; 69: 1629-35.

47. An MM, Zou Z, Shen H, Zhang JD, Cao YB, Jiang YY. The addition of tocilizumab to DMARD therapy for rheumatoid arthritis: a meta-analysis of randomized controlled trials. Eur J Clin Pharmacol. 2010; 66: 49-59.

48. Moreland LW, O'Dell JR, Paulus HE, Curtis JR, Bathon JM, St Clair EW, et al. A randomized comparative effectiveness study of oral triple therapy versus etanercept plus methotrexate in early aggressive rheumatoid arthritis: the treatment of Early Aggressive Rheumatoid Arthritis Trial. Arthritis Rheum. 2012; 64: 2824-35.

49. McLean-Tooke A, Aldridge C, Waugh S, Spickett GP, Kay L. Methotrexate, rheumatoid arthritis and infection risk: what is the evidence? Rheumatology (Oxford). 2009; 48: 867-71.

50. Reynolds ND, Edwards MH, Hull RG, Ledingham JM. Leucopenia in rheumatoid arthritis patients prescribed methotrexate as combination or monotherapy. BSR and BHPR Annual meetings 2009. Poster 108.

51. Mukhtyar C, Guillevin L, Cid MC, Dasgupta B, de Groot K, Gross W, et al. EULAR recommendations for the management of primary small and medium vessel vasculitis. Ann Rheum Dis. 2009; 68: 310-7.

52. Hernández-Rodríguez J, Cid MC, López-Soto A, Espigol-Frigolé G, Bosch X. Treatment of polymyalgia rheumatica: a systematic review. Arch Intern Med. 2009; 169: 1839-50.

53. Cimmino MA, Salvarani C, Macchioni P, Gerli R, Bartoloni Bocci E, Montecucco C, et al. Long-term follow-up of polymyalgia rheumatica patients treated with methotrexate and steroids. Clin Exp Rheumatol. 2008; 26: 395-400.

54. Winzer M, Aringer M. Use of methotrexate in patients with systemic lupus erythematosus and primary Sjögren's syndrome. Clin Exp Rheumatol. 2010; 28: 156S-9S.

55. Pagnoux C, Mahr A, Hamidou MA, Boffa JJ, Ruivard M, Ducroix JP, et al. Azathioprine or methotrexate maintenance for ANCA-associated vasculitis. N Engl J Med. 2008; 359: 2790-803.

56. Ash Z, Gaujoux-Viala C, Gossec L, Hensor EM, FitzGerald O, Winthrop K, et al. A sy- 
stematic literature review of drug therapies for the treatment of psoriatic arthritis: current evidence and meta-analysis informing the EULAR recommendations for the management of psoriatic arthritis. Ann Rheum Dis. 2012; 71: 319-26.

57. Scarpa R, Peluso R, Atteno M, Manguso F, Spanò $\mathrm{A}$, Iervolino $\mathrm{S}$, et al. The effectiveness of a traditional therapeutical approach in early psoriatic arthritis: results of a pilot randomised 6-month trial with methotrexate. Clin Rheumatol. 2008; 27: 823-6.

58. Chandran V, Schentag CT, Gladman DD. Reappraisal of the effectiveness of methotrexate in psoriatic arthritis: results from a longitudinal observational cohort. J Rheumatol. 2008; 35: 469-71.

59. Lie E, van der Heijde D, Uhlig T, Heiberg MS, Koldingsnes W, Rødevand E, et al. Effectiveness and retention rates of methotrexate in psoriatic arthritis in comparison with methotrexate-treated patients with rheumatoid arthritis. Ann Rheum Dis. 2010; 69: 671-6.

60. Ceponis A, Kavanaugh A. Use of methotrexate in patients with psoriatic arthritis. Clin Exp Rheumatol. 2010; 28: 132S-7S.

61. Kingsley GH, Kowalczyk A, Taylor H, Ibrahim F, Packham JC, McHugh NJ, et al. A randomized placebo-controlled trial of methotrexate in psoriatic arthritis. Rheumatology (Oxford). 2012; 51: 1368-77.

62. Kowal-Bielecka O, Landewé R, Avouac J, Chwiesko S, Miniati I, Czirjak L, et al. EULAR recommendations for the treatment of systemic sclerosis: a report from the EULAR Scleroderma Trials and Research group (EUSTAR). Ann Rheum Dis. 2009; 68: 620-8.

63. Tiippana-Kinnunen T, Paimela L, Kautiainen H, Laasonen L, Leirisalo-Repo M. Can disease-modifying anti-rheumatic drugs be discontinued in long-standing rheumatoid arthritis? A 15 years follow-up. Scand J Rheumatol. 2010; 39: 12-8.

64. Klarenbeek NB, van der Kooij SM, Güler-
Yüksel M, van Groenendael JH, Han KH, Kerstens PJ, et al. Discontinuing treatment in patients with rheumatoid arthritis in sustained clinical remission: exploratory analyses from the BeSt study. Ann Rheum Dis. 2011; 70: 315-9.

65. Hetland ML, Stengaard-Pedersen K, Junker P, Østergaard M, Ejbjerg BJ, Jacobsen S, et al. Radiographic progression and remission rates in early rheumatoid arthritis - MRI bone oedema and anti-CCP predicted radiographic progression in the 5-year extension of the double-blind randomised CIMESTRA trial. Ann Rheum Dis. 2010; 69: 1789-95.

66. Bykerk VP. Rheumatoid arthritis: 2011 remission criteria are a new benchmark for RA therapy. Nat Rev Rheumatol. 2011; 7: 317-8.

67. Goekoop-Ruiterman YP, Huizinga TW. Rheumatoid arthritis: can we achieve true drug-free remission in patients with RA? Nat Rev Rheumatol. 2010; 6: 68-70.

68. Canhão H, Santos MJ, Costa L, Bogas M, Mourão AF, Machado P, et al. Portuguese recommendations for the use of methotrexate in the treatment of rheumatoid arthritis. Acta Reumatol Port. 2009; 34: 78-95.

69. Nóvoa Medina FJ, Francisco Hernández F. Can the medication in patients with rheumatoidarthritis in remission be stopped? Reumatol Clin. 2012; 8: 39-41.

70. van der Kooij SM, Goekoop-Ruiterman YP, de Vries-Bouwstra JK, Güler-Yüksel M, Zwinderman AH, Kerstens PJ, et al. Drug-free remission, functioning and radiographic damage after 4 years of response-driven treatment in patients with recent-onset rheumatoid arthritis. Ann Rheum Dis. 2009; 68: 914-21.

71. Singh JA, Furst DE, Bharat A, Curtis JR, Kavanaugh AF, Kremer JM, et al. 2012 update of the 2008 American College of Rheumatology recommendations for the use of disease-modifying antirheumatic drugs and biologic agents in the treatment of rheumatoid arthritis. Arthritis Care Res (Hoboken). 2012; 64: 625-39. 